\title{
ZERO WASTE (RESÍDUO ZERO): uma abordagem sustentável para confecção de vestimentas
}

\author{
Francis da Silveira Firmo \\ UFMG \\ fsfirmo@gmail.com
}

\begin{abstract}
Resumo: A proposta deste trabalho é dar uma contribuição para a divulgação do design Zero Waste (também conhecido como Resíduo Zero), abordagem em que os designers de moda, durante o processo criativo, elaboram seus projetos visando antecipadamente a redução do resíduo têxtil do processo produtivo. Neste artigo após uma retomada na historiografia do vestuário de seu uso ao longo dos diversos séculos foram realizadas descrições e apresentações de diversos profissionais que apresentam em seus projetos de vestuário o conceito de Zero Waste, as diferentes técnicas que são utilizadas e enfoques que são utilizados por eles e as questões fundamentais relativas a essa metodologia.
\end{abstract}

Palavras-chave: Design, sustentabilidade, moda, modelagem, Zero Waste

\begin{abstract}
The purpose of this paper is to give a contribution to the dissemination of the design Zero Waste, approach in which fashion designers during the creative process developed their projects in order to advance the reduction of textile waste from the production process. In this article there are descriptions of various professional presentations that that feature in their designs of clothing the concept of Zero Waste and the fundamental issues relating to this methodology.
\end{abstract}

Key word: Design, sustentability, fashion, modeling, Zero Waste

\section{INTRODUÇÃO}

O sistema da moda está inserido dentro da sociedade de consumo. A cada dia o ciclo de seu produto se torna cada vez menor, fazendo com que haja lançamentos freqüentes e como consequência, a substituição de peças que não mais estão sendo utilizadas (MCQUILLAN \& RISSANEN, 2011). A indústria do vestuário descarta cerca de $15 \%$ do que produz, o que a longo prazo gera um problema de grandes proporções: este prejuízo não é só financeiro como também socioambiental.

Dentro da consciência da gravidade desta situação, vista como natural por muitos dos que integram o processo de produção é que surge o Zero Waste, também denominado Resíduo Zero, princípio que busca eliminar o descarte de tecido no 
processo produtivo. Envolve uma maneira diferente de atuar por parte do designer, já que é dois importantes momentos - o do projeto de criação do vestuário e o do planejamento da redução do descarte - ocorrem simultaneamente.

O Zero Waste ainda está sendo difundido no mundo da moda. Inicialmente foi utilizado pelos europeus, mas já transcende o Velho Continente. Mesmo inserido no conteúdo de escolas de desenho nos Estados Unidos e de ter peças elaboradas segundo esta abordagem presentes nas Semanas da Moda de Londres, ainda há pouca bibliografia sobre o tema. A relevância deste artigo está localizada no fato de buscar sistematizar e apresentar as diferentes abordagens dessa metodologia, que ainda é pouco conhecida, principalmente no meio acadêmico brasileiro, para que futuros designers de moda, entre outros, possam ter acesso a ela.

A proposta de muitos que trabalham com a metodologia do Zero Waste inserido no processo de produção de peças de vestuário na contemporaneidade é apresentá-lo não como um elemento que impede a criatividade, mas como um novo modo de trabalho criativo, viável, no qual as diversas etapas produtivas se encontram interligadas para a confecção de roupas sustentáveis e com informações de moda. A princípio abordaremos historicamente o aproveitamento integral do tecido e o seu uso por parte de alguns criadores de moda. Portanto serão realizadas descrições sobre o processo criativo dos principais designers que trabalham dentro do enfoque Zero Waste (Resíduo Zero), explicitando o seu modo de projetar o vestuário. Também serão levantadas questões fundamentais pertinentes a essa concepção de design e sua inserção no processo produtivo.

\section{ZERO WASTE}

Zero Waste é considerado como

uma meta que é ética, econômica, eficiente, visionária, para orientar as pessoas em mudar seus estilos de vida e práticas sustentáveis para emular ciclos naturais, onde todos os materiais descartados são projetados para tornarem-se recurso para outros usarem. (DUARTE, 2013)

Isso significa que estão envolvidos diversos fatores dentro desse enfoque, sendo que um deles, o ético, se relaciona diretamente com uma visão sustentável de mundo. Mais do que isso essa metodologia "significa projetar e gerenciar produtos e recursos para evitar e eliminar sistematicamente o volume e a toxidade dos resíduos e materiais, conservar e recuperar todos os recursos, e não queimar ou enterrá-los" (DUARTE, 2013).

Esta visão é contemporânea, e implica que o designer, durante o momento criativo, já tenha em mente outras etapas do processo produtivo, como uma modelagem que possibilita o encaixe perfeito das peças que compõe o vestuário a ser projetado, de modo que não deve ocorrer nenhum descarte do tecido com o qual ele será confeccionado. Portanto para que se logre este fim, diferentes metodologias podem ser utilizadas - por exemplo, modelagem plana, tridimensional - para que a elaboração da peça projetada.

Portanto, a ideia por trás do Zero Waste - o completo aproveitamento do tecido - vem sido aplicada, ao longo da história, na confecção do vestuário. Desde a Antiguidade, sempre houve povos que, com peças retangulares dispostas junto ao corpo, o cobriram. Segundo Köhler (2009) os egípcios do Antigo Império (c. 3.000 a.C.) usavam uma tanga e manta na qual se embrulhavam. Mais tarde (c. 1.000 a.C.) foi introduzido o kalasiris, que nada mais era que uma túnica, semelhante a um saco, 
costurado lateralmente: alguns com orifícios para as mangas e as cabeças, outros usados na altura do dorso ou da cintura. Os sírios e fenícios, em 2.300 a. C., se enrolavam com tecido na altura da axila e uma das suas extremidades era jogada para trás, sobre o ombro, para ser unida à outra ponta: também vestiam uma capa, sobre o ombro. Os hebreus (1.000 a.C), além de uma camisa, usavam um tecido retangular enrolado ao qual ajustavam com um cinto junto ao corpo. Com o passar do tempo ganhou a forma de caftã - que posteriormente tornou-se uma sobreveste, com as laterais abertas. Os gregos, por sua vez, trajavam três peças: o quíton - composta por dois retângulos, pregueados, unidos por broches ou elementos metálicos -, uma sobreveste (o peplo) - em formato tubular e ajustável no ombro - e uma capa (a clâmide), jogada no corpo. Enquanto a estrutura do vestuário permanecia a mesma, as dobras e pregas feitas pelos usuários para o ajuste ao vestir, variavam segundo a época, sofrendo alterações durante o passar dos séculos.

Se essas peças já não mais constam do vestuário atual, há outras que perduram até hoje e que seguem a modelagem de completo aproveitamento do tecido. É o caso do traje típico japonês, o quimono, que mantêm a mesma estrutura de seus primórdios, confeccionado a partir de peças retangulares. O corte está condicionado à largura do tear e o comprimento varia de acordo com o tamanho do usuário. Há uma costura no meio das costas, além das laterais. Para os ombros, faz-se uma abertura, traçando uma reta perpendicular à lateral do quimono. A parte do tecido que é utilizada para a gola, os painéis (okumi), as mangas e a faixa são retiradas das extremidades do tecido, que é completamente aproveitado. Outra peça tradicional que perdura até os nossos dias é o sári, usado pelas indianas. Composto por um tecido, de 4 a 9 metros de comprimento enrolado junto ao corpo feminino, possibilita variadas formas de amarração. Além dos casos já citados, nos trajes e alguns acessórios dos índios da América Latina há o aproveitamento integral do tecido, ao explorar a forma retangular em ponchos, mantas, e a quepirina, peça na qual as incas levam o material que coletam no campo e no qual também trazem os seus filhos junto ao seu corpo.

A partir da Idade Média a vestimenta passou por uma importante transformação: devido o contato com o Oriente, onde a técnica do corte do tecido já era adotada desde 600 a.C., as peças do vestuário tornam-se mais ajustadas ao corpo do usuário. Ele, porém, com suas curvas e volumem, exigia uma modelagem da indumentária mais elaborada. Foi no Renascimento, "onde os grandes avanços ocorridos neste período representam a base de todos os processos metodológicos de modelagem da atualidade" (SOARES, 2009, p.242), que efetivamente o tecido é ajustado ao corpo através de cortes e recortes no tecido. O surgimento dos moldes e da arte da modelagem marcam o início da "personalização do vestuário" - nesse momento não havia preocupação com o descarte de tecidos não aproveitados na elaboração do modelo desejado.

Pode-se dizer que a precursora do reaproveitamento do tecido na confecção de roupas foi Madame Vionnet (1876-1975). Em 1912 decidiu retomar as túnicas clássicas, gregas e egípcias, e propôs peças fluidas, drapeadas, numa redescoberta das formas femininas, apesar da silhueta de linha reta de seus modelos. Vionnet trabalhou no viés, o que deu leveza às suas criações. Seus tecidos possuíam mais de 2 metros de largura e usava em seus modelos formas geométricas (Figura 1) - quadrado, retângulo, triângulo e até mesmo a espiral- além das formas orgânicas. Diferente dos outros 
estilistas, não realizava nenhum croqui: trabalhava diretamente sobre um manequim em miniatura, utilizando a técnica que hoje chamamos de moulage: passando o modelo para escala humana assim que obtinha o resultado desejado. É importante comentar que nem todas as suas criações usavam integralmente o tecido. Além das drapeados, dobras eram empregadas e embelezavam pelo efeito produzido. Segundo Mendes \& Haye $(2009,90-91)$ "Vionnet era excepcional pelo fato de não costurar seus drapeados e esperar que as clientes executassem uma série de manobras habilidosas para alcançar o visual desejado."- o que a faz ser sempre citada por aqueles que estudam o Waste Zero.

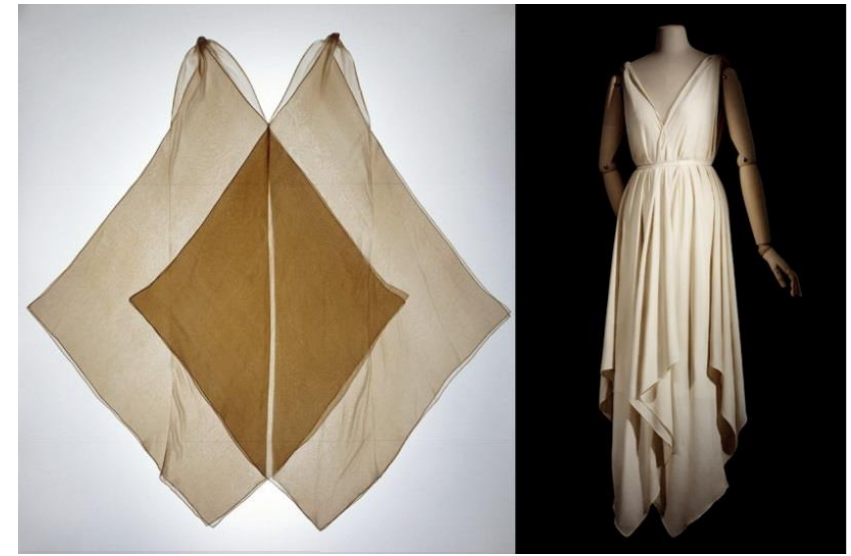

Figura 1 - Criação de Madame Vionnet a partir de formas geométricas. Fonte: KIRKE, 1998.

Outro nome que merece ser mencionado é o da estilista Claire McCardell (1905-1958), que na década de 20, foi muito importante para a indústria da moda americana do pós-guerra. Buscava a funcionalidade das peças e o conforto, sem desprezar a feminilidade (Figura 2). Influenciada por Madame Vionnet, adotou o corte viés e roupas que envolviam o corpo feminino, fechadas por nós e/ou amarrações. Assim como a francesa, trabalhou com a silhueta reta, típica dos anos 20, e criou modelos sob uma perspectiva de economia da matéria-prima no tocante ao descarte de material. Usou tecidos de maneira inédita, chegando inclusive a criar um vestido em que não se distingue a frente das costas, onde a cintura não era determinada e em que as amarrações é que possibilitavam o seu uso diferenciado. Foi McCardell quem inventou o vestido envelope (BAUDOT, 2008). Embora nem todas as suas peças o aproveitamento do tecido era integral, conseguiu aproveitá-lo de modo muito mais racional em uma época de escassez, fazendo uso de muitas amarrações, drapeados, cortes geométricos, bolsos chapados etc em suas criações.

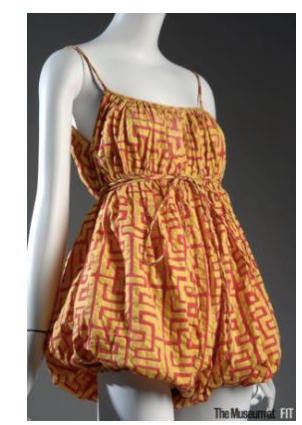

Figura 2 - Roupa de banho criada por Claire McCardell. Fonte: FIT Museum. Disponível em <http://www.fitnyc.edu/museum.asp> 
A grande pioneira do Zero Waste é a canadense Dorothy Burnham (1911-2004), que em 1973 publicou um livro chamado Cut my cote (Figura 3), em que sistematizou suas pesquisas históricas sobre o vestuário, abordando como cada peça pode ser confeccionada, os tecidos a serem utilizados, sua modelagem e o modo como deve ser montada (costurada) a partir da reprodução de modelos usados durante o longo da história da moda, de modo a facilitar a reconstrução das peças. Salientou - e é perceptível - como no vestuário tradicional havia um uso racional do tecido, sem que o a roupa deixasse de apresentar outros elementos à sua função, como por exemplo, a ornamentação, diferenciação simbólica, filiação social (JONES, 2005). Afirmou que, com o passar do tempo, o desperdício passou a ser um elemento frequente e até ignorado no processo produtivo. Para ela, ao oferecer peças onde o corte e o encaixe das peças são realizados com total aproveitamento do tecido, agrega-se outro valor ao produto: o da sustentabilidade.

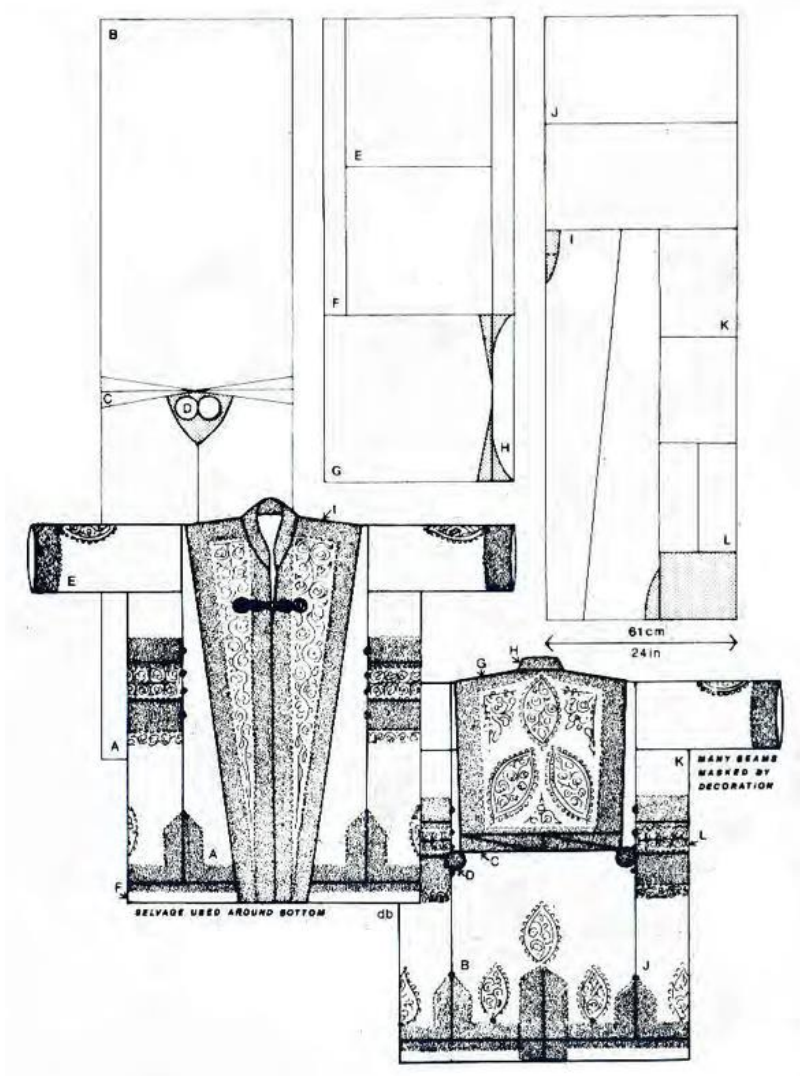

Figura 3 - Casaco festivo de fazendeiro da Transilvânia de 1890 . Contracapa do livro Cut my cote. Disponível em <http://theperfectnose.wordpress.com/2013/01/10/book-review-cut-my-cote-bydorothy-k-burnham/>

Um grande divulgador das ideias do Zero Waste foi Bernard Rudofsky (19051988), arquiteto, filósofo, designer, curador, devido às várias mostras instigantes que montou. Em 1947 em Are Clothes Modern? expôs, no Modern Museum de Nova York, várias peças de Claire McCardell e outros, com destaque para as que havia aproveitamento do tecido de modo completo ou mais racional. Na ocasião havia proferido uma polêmica palestra em que questionava o vestir da época, por ele 
considerado inadequado, e lançou suas reflexões pessoais sobre o vestir e o fazer no setor do vestuário.

Outras experiências de moda mais sustentável surgem no final do século XX em diversos locais do mundo, com predominância nos países europeus. Apesar de numericamente inferior, os Estados Unidos tem investido muito nesta área, inclusive com a criação de cursos dentro da grade curricular da Parson The New School of Design, escola de moda e design de Nova York, que oferta a disciplina de Zero Waste à comunidade acadêmica, possibilitando que os designers produzam peças que pensam na eliminação do desperdício de tecido desde o seu início do processo criativo. Dessa forma a planificação e o corte são etapas que surgem junto à criação e não como mais uma das etapas do processo de produção. Desde o início o projeto está pensado com base na sustentabilidade, no sentido de não produzir nenhum resíduo, ou de reduzi-lo ao máximo. Nesse enfoque toma-se como ponto de partida a visualização prévia em 2 e 3 dimensões, uma vez que é um planejamento integrado da criação, modelagem e planificação do corte das peças, sem descuidar da preocupação com a presença de informação de moda. Para a viabilização dessa metodologia, o projeto do design - a peça do vestuário - pode ter como ponto de partida a elaboração do molde do modelo e a sua confecção. Em outros casos, o caminho é o inverso: os moldes são traçados após serem aprovados em um projeto realizado tridimensionalmente. São muitas as maneiras como a abordagem do Zero Waste é utilizada. Também são vários os nomes dos profissionais que a pesquisam. Abordaremos apenas os que se destacam internacionalmente na busca pela redução do desperdício têxtil.

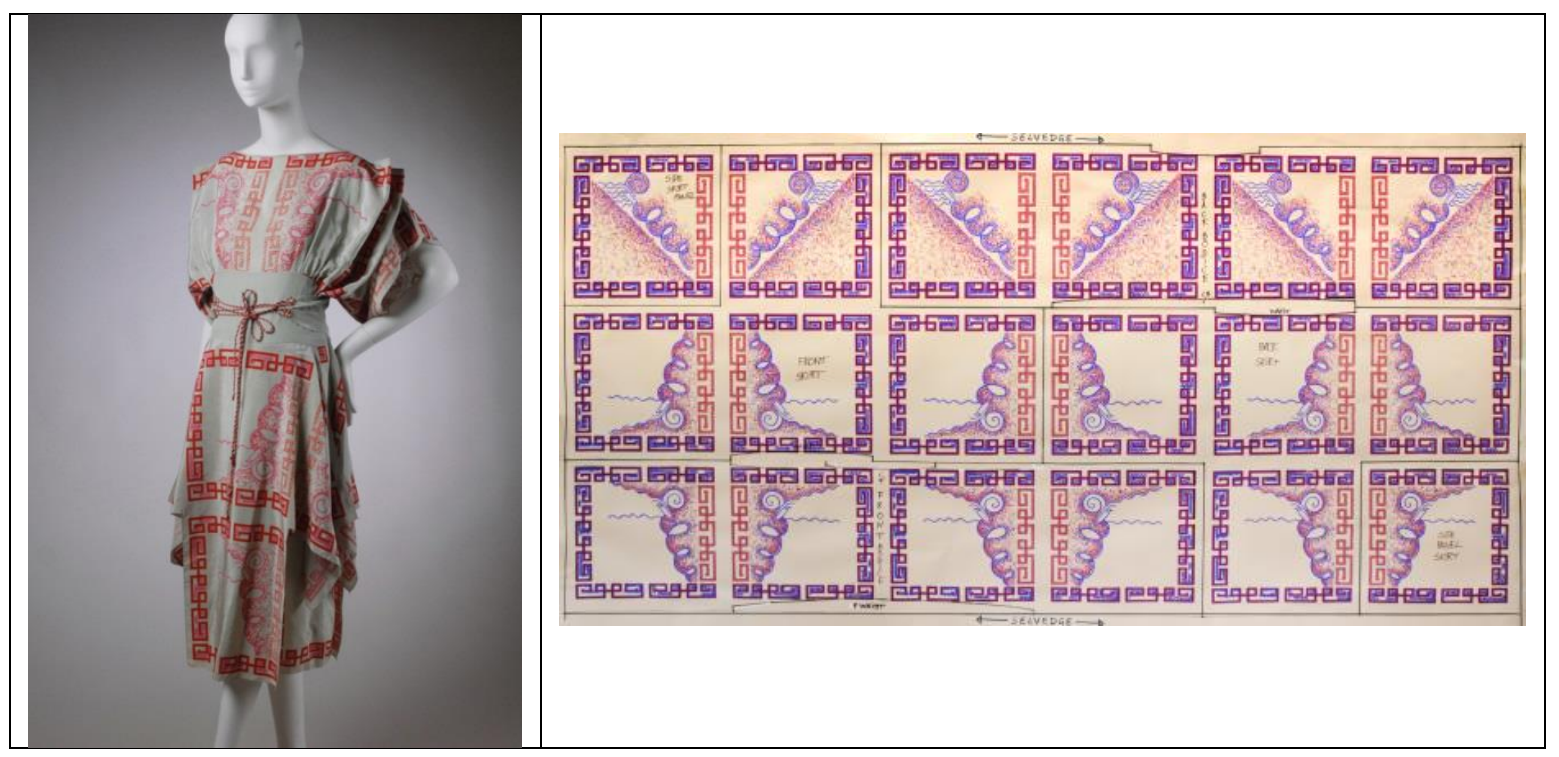

Figuras 4 e 5 - Vestido e estamparia em tecido de seda para o vestido Chinese Squares, coleção primavera-verão 1980 Copyright Zandra $\quad$ Rhodes. Disponível em <http://hollymcquillan.com/2011/03/28/yieldzandra-rhodes-chinese-squares/>

A inglesa Zandra Rhodes é uma das pioneiras na confecção de peças do vestuário elaborada segundo o enfoque Zero Waste. Desde os anos 70 faz uso de material orgânico em suas criações, utiliza trabalhos manuais (bordados, tricô, crochê) em suas criações, além de estampas diferenciadas - é também uma designer têxtil. Incursiona nesse enfoque principalmente para o máximo do aproveitamento das estampas presentes nos tecidos. Este foi o caso do vestido Chinese Squares (Figuras 4 e 
5), onde o corte geométrico do tecido foi realizado para não perder o que foi pintado a mão, valorizando inteiramente a estampa: esta se encontra visível, em uma peça que envolve o corpo feminino, sem nenhum tipo de costura. Apenas as ourelas foram retiradas. A sua atuação dentro do Zero Waste se dá pela utilização da modelagem plana, técnica em que os moldes são elaborados em função das medidas do corpo humano e dispostos sobre o tecido para serem cortados.

O finlandês Timo Rissanen é o grande nome nos Estados Unidos. Professor da escola Parsons (Nova York), trabalha com Zero Waste e é um especialista da área. Sua tese de graduação foi sobre Madeleine Vionnet e como ela influenciou estilistas como Claire McCardell, Issey Miyake e Galliano. A partir desse estudo é que percebeu a viabilidade da eliminação completa de resíduos no design de moda e decidiu retomar o modo como eram confeccionadas as peças do vestuário na Antiguidade, para estudálas e colocá-las em prática. Ao aprofundar suas investigações, Rissanen percebeu que havia a necessidade de adaptar o seu olhar. Parte do planejamento: usa a modelagem plana e o encaixe das bases dos moldes como um quebra-cabeça, dispondo-as sobre o tecido e estudando as diversas alternativas visando o aproveitamento do mesmo, na criação da peça de roupa desejada, conforme o modelo projetado. Ao conseguir realizar esta primeira fase é que são definidos e desenhados os moldes definitivos e o próximo passo é o encaixe. Rinassen utilizou esse método em sua grife, denominada Usvsu, (Austrália) - voltada para o segmento masculino -, durante os anos 2000 a 2004. A sua experiência prática e o doutorado na área - Fashion Creation Without Fabric Waste Creation - o tornam uma importante referência no tema de sustentabilidade e moda.

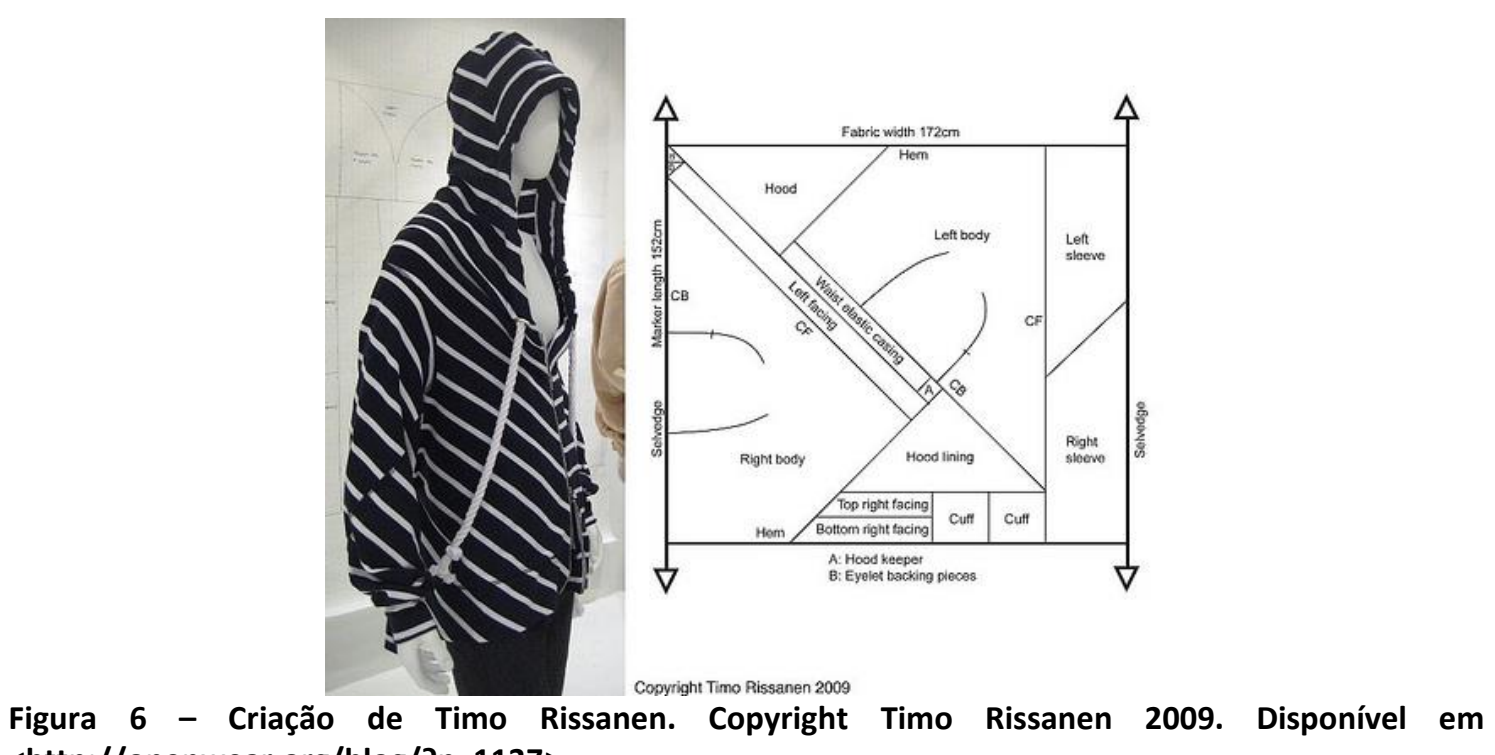
<http://openwear.org/blog/?p=1137>

Holly McQuillam, neozelandesa, sempre foi sensível à questão ambiental e de sustentabilidade. Para ela Zero Waste é uma forma de buscar um novo modelo de produção e criação no design de moda, pela completa eliminação de desperdício. Sente-se desafiada por buscar novas maneiras de empregar este método, que implica um projeto de criação melhor planejado: seu processo produtivo tem com ponto de partida uma ideia bastante ampla - uma peça ou mesmo um detalhe de uma roupa, ou mesmo uma silhueta definida a partir de uma parte do corpo. Só então ela começa 
seus estudos de como se dará o encaixe dos moldes, levando em conta o tecido a ser utilizado - largura e caimento (Figura 6). MCQuillam faz todo o projeto no computador, e nem sempre usa as bases para elaborar o molde. Planeja previamente os locais onde haverá costura, define as formas e linhas para criar a peça que vista o corpo da forma mais ou menos esperada: isso porque essa etapa corresponde a $85 \%$ do projeto. $O$ restante está compreendido na experimentação: um molde em escala reduzida é traçado para que haja a pilotagem e sejam realizados os prováveis acertos. Muitas vezes a tela usada é em tamanho natural para que o conforto seja avaliado item que a estilista preza tanto quanto o Zero Waste. Portanto para essa fase ela faz questão de testar e avaliar o resultado em si mesma. Segundo seu ponto de vista esse método é uma nova forma de atuar: envolve mudança de foco no processo criativo, exige o controle total do designer sobre a sua criação para que faça o aproveitamento de tecido com o surgimento de formas, linhas e espaços inusitados.

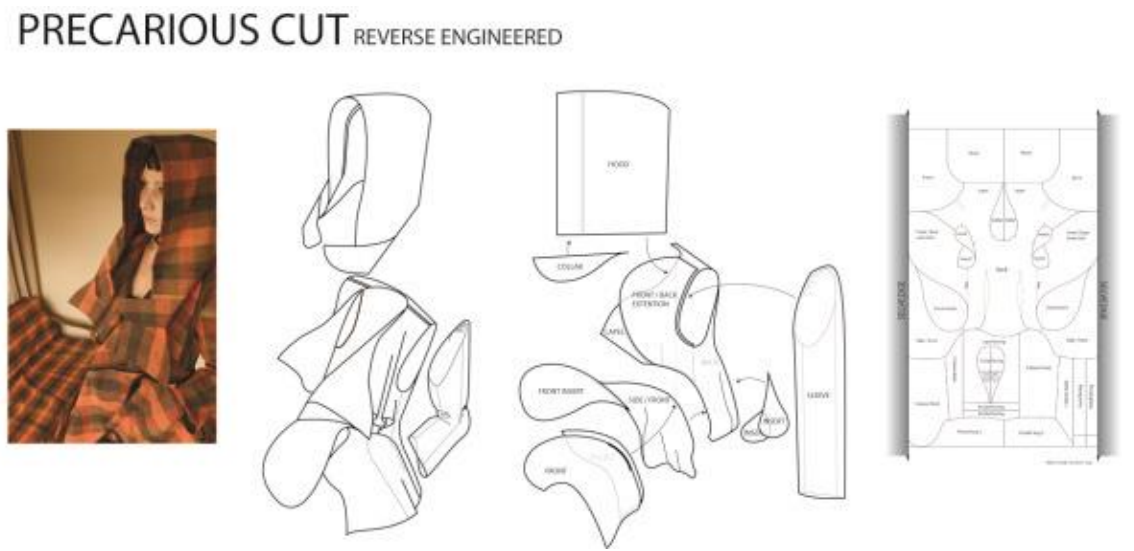

Figura 7 - Criação de Holly McQuillam com o uso do processo Precarious Cut. Disponível em <http://hollymcquillan.com/2009/09/14/precarious-cut-reverse-engineered-zero-waste-garment/>

O estilista britânico Julian Roberts é inventor de um método, com o qual trabalha desde 1999, diferente de todos os já mencionados: o Subtraction Cutting. Ele parte do tecido: o molde é representado como um espaço negativo, ou seja, o espaço que dele será subtraído. Criador da escola de moda na Hertfordshire University, Reino Unido, realiza palestras em todo mundo divulgando o seu método, que permite que pessoas, sem conhecimento de modelagem e sem o uso de cálculos matemáticos construam criativas peças do vestuário. O ponto de partida é o espaço oco da roupa, que é ocupado pelo corpo: não há a preocupação em definir previamente o que é frente ou costas, por exemplo. É um trabalho realizado de dentro para fora que usa este vazio - o espaço negativo -, subtraído do tecido: esta é a razão do nome de seu método, o Subtraction cutting (Figura 7 e 8). A partir deste espaço se concebe a modelagem dentro de uma perspectiva tridimensional, com a incorporação do próprio corpo no processo, que passa a ser usado como referência, sem o uso de outro instrumento de medição além dele. É um método cujo resultado é como ato performático do cortar, uma vez que não há um roteiro pré-estabelecido a ser seguido: ele decorre do próprio ato do fazer. Com a sua difusão, diversos elementos vêm sendo acrescentados a ele e tem possibilitado o surgimento de diversas novas formas de construção do vestuário. 

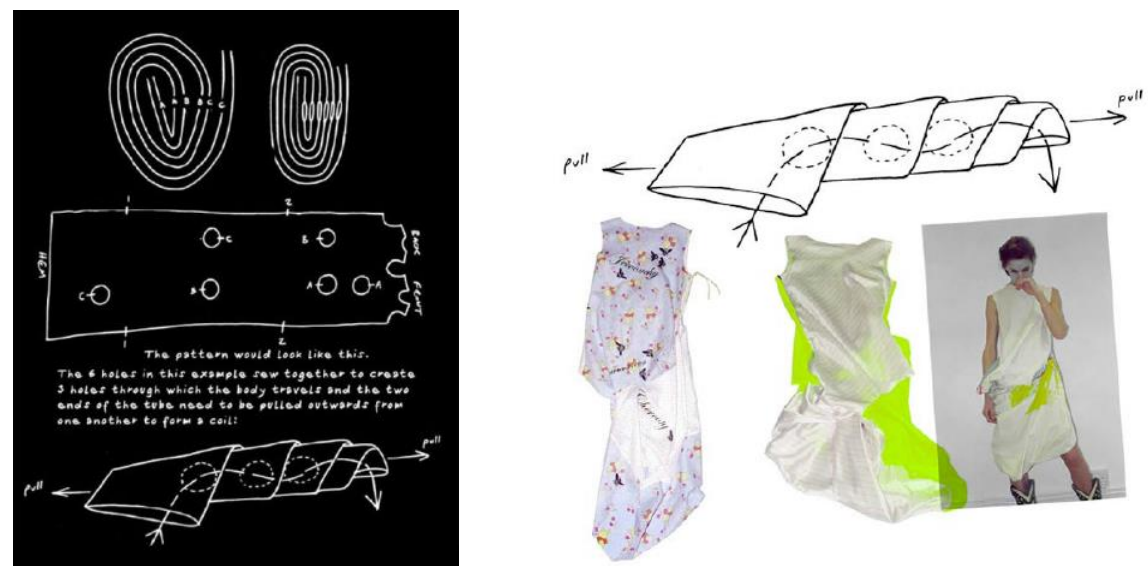

Figuras 8 e 9 - Subtraction Cutting: processo criativo de Julian Roberts, do tecido à vestimenta. A partir do tecido são realizados os cortes e esses vazios serão preenchidos pelo corpo e aplique de tecidos diferenciados. Disponível respectivamente em <http://openwear.org/blog/?p=1249> (2011) e <http://subtractioncutting.tumblr.com/>

O inglês Mark Liu, ex-aluno da Saint Martin's College, desde 2007 trabalha com o Zero Waste. Este inclusive foi tema de sua coleção de estréia na London Fashion Week, onde obteve, tanto ele como esse método, grande visibilidade. Atualmente é um dos grandes nomes na Inglaterra. Faz uso de pregas, de pontas arrendondadas e sua modelagem aproveita totalmente o tecido, através do princípio do quebra-cabeça, do encaixe preciso das peças, com o uso do corte a laser para maior precisão e menor perda de tecido.

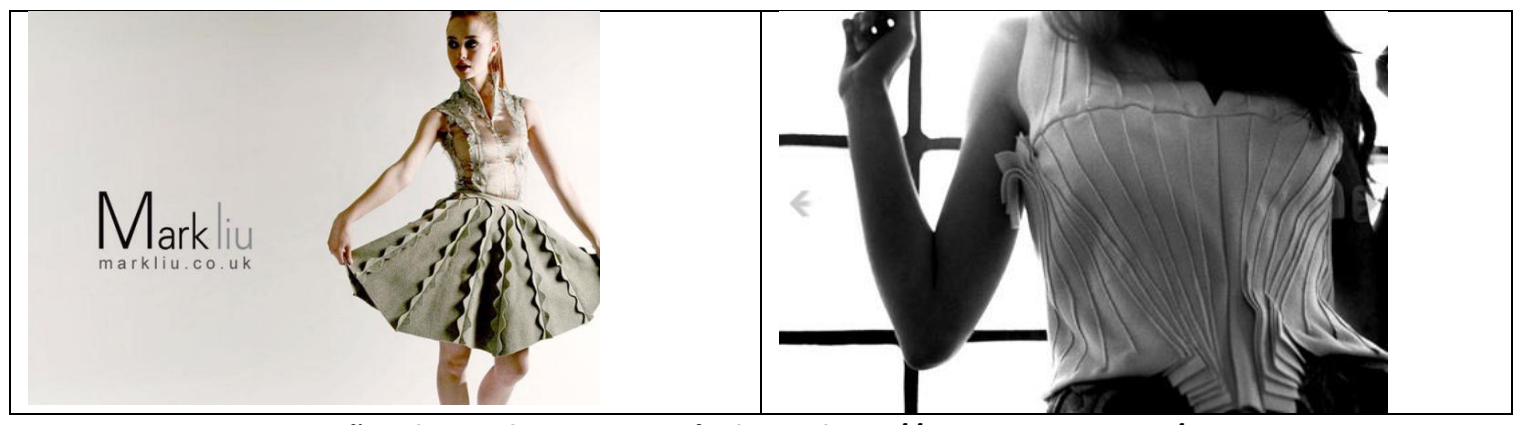

Figuras 10 e 11 - Criações de Mark Liu. Disponível em <http://www.stique.com/>

No continente americano, fora do circuito de língua inglesa, é interessante citar uma estilista com o foco diferente de todos os que já foram citados. Carla Fernandez, mexicana, traz em suas criações a presença do artesanato e das técnicas têxteis utilizadas pelas comunidades indígenas de seu país, que trabalham com as formas geométricas e tecidos artesanais confeccionados em teares horizontais domésticos. Sua grife de moda ecológica incorporou a experiência têxtil pré-hispânica dos maias de corte de tecidos, a partir das formas retangulares e quadradas que compõe peças como a huipil, blusa ou vestido completamente adornado por trabalhos artesanais, semelhante a uma túnica, bastante utilizado pelas índias do México. A designer traduziu e criou, a partir dessas formas, peças com informações de moda voltadas para as pessoas da contemporaneidade. Também é adepta da prática do comércio justo, 0 que a insere dentro do segmento de moda voltada à sustentabilidade. Segundo ela a modelagem indígena se configura como "uma espécie de origami têxtil que a partir do tratamento diferente que lhe é dado a um tecido quadrado, se tona possível todas as 
outras formas geométricas, "una especie de origami textil, que a partir del diferente tratamiento que se le da a un lienzo cuadrado, se consiguen todas las demás figuras geométricas" (FERNÁNDEZ, 2006, 11), modelagem esta preocupada em não desperdiçar o material têxtil que produzem com suas próprias mãos.

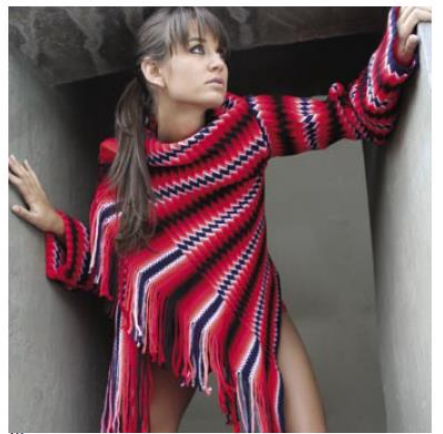

Figuras 11 e 12 - Criações de Carla Fernández <http://carlafernandez.com/downloads/libro_carla_fernandez.pdf>

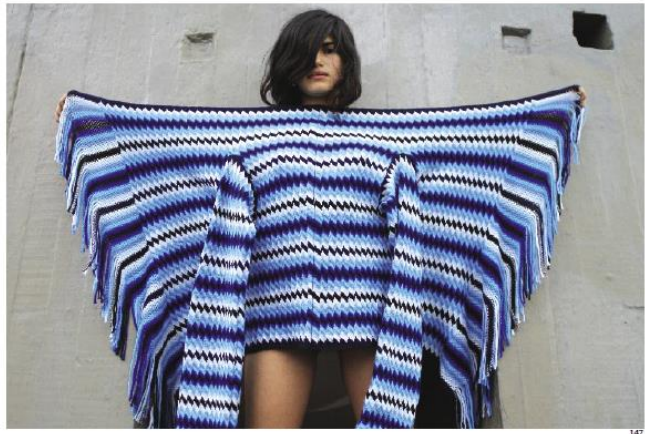

(2005). Disponível em

Para finalizar, vamos ilustrar com um caso brasileiro apresentado por Rüthschilling \& Anicet (2013) em que o enfoque Zero Waste está presente em um atelier de investigação têxtil denominado Contextura,

empresa híbrida que desenvolve produtos de moda sustentável, decoração e artes, presta serviçoes de design de superfície, além de funcionar como laboratório de experimentos que fundamental a pesquisa científica na áreas de moda, design de superfície e sustentabilidade (RÜTHSCHILLING \& ANICET 2013, p.26).

Nele o Zero Waste, da forma como vem sendo apresentado neste artigo, está presente nos momentos em que a moulage é utilizada com o intuito de reduzir ao máximo o resíduo têxtil. A empresa também emprega as sobras do seu processo produtivo, as vezes da própria peça que o receberá, no tratamento de superfície e embelezamento, através de colagens de resíduos. A preocupação com a sustentabilidade norteia o trabalho desse atelier: há o reaproveitamento de materiais descartados e a concepção de uso de todo o material empregado sem que haja desperdício.

Pode-se perceber que na busca pela redução do resíduo têxtil nem todos os que foram citados neste artigo trabalham exclusivamente com o design Zero Waste, uma vez que sua aplicabilidade não é tão simples. Primeiro requer uma mudança completa tanto do processo produtivo como do processo de criação. Hoje o croqui é o ponto de partida, com a livre criação do desenho, realizado muitas vezes sem que o tecido tenha sido escolhido, e muitas vezes sem que o designer toque a peça enquanto ela é executada. À etapa da modelagem cabe a sua materialização, seja através da modelagem plana ou da tridimensional. Para testar se corresponde às expectativas do seu criador e evitar possíveis erros, o molde é disposto sobre o tecido de modo a garantir o menor desperdício (encaixe), para então ser cortado e costurado: a peça piloto. Aprovada, será confeccionada em vários tamanhos pré-estabelecidos. No caso do enfoque do Zero Waste a criação já tem de prever e antever as etapas de encaixe/corte e também a da modelagem. Tem de ser projetado todo o percurso da confecção do vestuário, partindo de uma visualização em terceira dimensão com previsão de sua realização, sem que haja descarte de tecido - ou, na sua impossibilidade, que este seja o mínimo possível. Nesse caso, as etapas se inter- 
relacionam: o encaixe /corte está diretamente relacionado à criação-planificação e essa a da modelagem e vice-versa. Nada pode ser pensado separadamente: tudo é simultâneo. Todas as modificações - de formas, os ajustes, as reformulações - devem estar previstas antes que seja cortado o tecido. Nesse processo criativo para alcançar a meta ética e eficiente do Zero Waste, faz-se necessário o emprego de diversas técnicas: para exemplificar, estiveram presentes neste artigo o subtraction cutting (Julian Roberts), precarious cut (Holly McQuillam), square-cut pattern (Vionnet, Claire McCardell, Carla Fernández), moulage (Contextura), entre outras

Dentro da mudança de paradigma que proporciona, um dos maiores diz respeito à eliminação da distância entre o designer tradicional - considerado como aquele que apenas cria - e a produção. Nessa abordagem do design as etapas existentes no processo convencional na indústria da moda passam a ocorrer simultaneamente, eliminando a sequência tradicional de criação-modelagemplanificação-encaixe-corte-pilotagem antes da aprovação. Ao comparar o processo de produção do vestuário feito com Zero Waste e o com o modo tradicional, vê-se que o segundo é mais ágil. Afinal, para que uma peça seja concretizada com total aproveitamento do tecido, leva-se muito mais tempo na elaboração desse projeto de completa utilização do tecido, exigindo planejamento, diálogo entre partes e trabalho em equipe, muitas vezes com resultados inesperados surgidos no momento do próprio fazer. Estes momentos tradicionalmente eram bem delimitados e sequenciais, não havendo momentos criativos nas etapas subsequentes à do design. Ademais, o conhecimento, uso e domínio da tecnologia são necessários nesse tipo de design: na elaboração de moldes via CAD com total aproveitamento do tecido, o corte a laser, etc.

Um fator desafiador quando se utiliza o Zero Waste é o da elaboração de peças com formas diferenciadas e belas, onde a presença de elementos com informação de moda em peças que, quase sempre nascem com a proposta de serem atemporais. Isto porque normalmente as pessoas que trabalham com esse tipo de design são sensíveis à questão da sustentabilidade, estando engajados em projetos de moda ecológica, preocupados com a matéria-prima a ser utilizada e os demais processos que cercam a produção do vestuário. São diversos os elementos a serem levados em consideração pelo designer no seu processo criativo, demandando também um conhecimento das cadeias produtivas dos seus parceiros. O uso maior do tempo no design Zero Waste usado em pesquisa em diferentes momentos e campos (o de tendências de moda, de materiais, de processos produtivos, de técnicas de design, de tecnologia e o do fazer) possibilita grandes inovações, porém numa temporalidade e custo que nem sempre são aceitos pelas indústrias da moda.

Há que se considerar que a cadeia produtiva está estruturada para o atual processo produtivo e, conservadora, evita possíveis riscos econômicos. Os tecidos e as máquinas que os produzem condicionam todo o processo de corte e, porque não dizer, o criativo. Muitas vezes a largura de um tecido impede que um modelo longo em godê seja confeccionado uma vez que não há o desejo de que haja uma emenda de tecido na parte inferior da saia. A realidade, portanto, acaba de certo modo por conformar a criação.

Fatores como esses desfavorecem a presença do Zero Waste como o único desing adotado no processo de confecção do vestuário. É fato que há preocupação com menor desperdício de materiais e com sua destinação adequada, seja pela 
reutilização ou pela reciclagem dos resíduos, o que já é uma pequena contribuição para a sustentabilidade do planeta.

\section{CONCLUSÃO}

Os designers que aplicam Zero Waste em suas produções ainda são muito poucos e vários deles não realizam todas as suas criações dentro desse enfoque. A indústria da moda ainda receia não conseguir um retorno comercial esperado ao adotá-lo e que as peças produzidas por este design não consigam ser aceitas pelo público não só pelo fator financeiro (seu custo traz embutido as horas de trabalho dedicadas ao seu planejamento e confecção), como pela existência de preconceito diante do segmento de moda sustentável, considerada por muitos como pouco inovadora no tocante a formas e modelos.

Apesar de tudo, o Zero Waste vem crescendo. A procura por cursos já é um indicativo, pois eles sensibilizam e possibilitam que mais pessoas atuem na desconstrução do processo tradicional de criação-modelagem-corte-pilotagem. A partir da visão que interliga as diversas etapas que se encontram separadas e também distantes umas das outras, instaura-se o diálogo, e conseqüentemente o ato construtivo ganha força e mais espaços, com possibilidade de uma maior inserção do resultado deste trabalho no mercado. Assim, as poucas empresas que comercializam peças de vestuário criadas dentre dos princípios do Zero Waste poderão enfrentar concorrência.

Ainda é muito prematuro, mas percebe-se que este design possibilita inovações em termos de formas e volumes. As empresas, sempre muito receosas diante de mudanças, aguardarão um pouco mais. Enquanto isso o grupo dos que nele atuam consolidam a sua prática, outros travam contato com ele através de palestras, cursos, mostras, sites, blogs etc e tornam-se agentes multiplicadores. A mudança de paradigmas se dá de modo lento e gradual. Pode ser que o meio-ambiente e a sustentabilidade cobrem uma aceleração desse processo. Muitos trabalhos ainda serão realizados na busca de divulgação e conhecimento das diversas técnicas e possibilidades do design Zero Waste.

\section{REFERÊNCIAS}

BAUDOT, François. Moda do Século. São Paulo: Cosac \& Naify Edições, 2008.

FERNÁNDEZ, Carla. Taller Flora. Coyoacán: Diamantina, 2006. Disponível na internet por http em: <http://carlafernandez.com/downloads/libro_carla_fernandez.pdf>. Acesso em 18 jul 2013.

JONES, Sue Jenkyn. Fashion design: manual do estilista. São Paulo: Cosac Naify, 2005.

Free-cutting. Disponível em <http://subtractioncutting.tumblr.com/>. Acesso em 17 abr 2014.

JULIAN ROBERT. Disponível em: <http://www.julianand.com/>. Acesso em 25 nov 2011. 
KIRKE, Betty. Madeleine Vionnet - Foreword by Issey Miyake. San Francisco: Chronicle Book LLC, 1998.

KÖHLER, Carl. História do vestuário. São Paulo: Martins Fontes, 2009.

LAVER, James. A roupa e a moda: uma história concisa. São Paulo: Companhia das Letras, 1989.

LUSSIER, Suzanne. Art Deco Fashion. London: Bullfinch Press, 2003.

MARK LIU. Disponível em: < http://www.stique.com/>. Acesso em 25 nov 2011.

MCQUILLAN, H.; RISSANEN, T. 2011. Yield: making fashion without making waste. Disponível na internet por http em:<http://yieldexhibition.com/yieldexhibitioncatalogue.pdf>. Acesso em 14 abr. 2013.

MCQUILLAN, HOLLY. Holly McQuillan. Disponível na internet por http em: <http://hollymcquillan.com/2011/03/28/yieldzandra-rhodes-chinese-squares/>.

Acesso em 22 nov 2011.

MENDES, Valerie; LA HAYE, Amy. A moda do século XX. São Paulo: Martins Fontes, 2009.

MUSEUM AT THE FASHION INSTITUTE OF TECHNOLOGY: The Museum at Fit: Disponível na internet por http em: <http://fashionmuseum.fitnyc.edu/>. Acesso em 20 out 2011.

PEREZ, lana Uliana. Nova abordagem para a prática do design de moda: processo zero waste. In: COLÓQUIO DE MODA, 9, 2013, Fortaleza. Anais. [ISSN 1982-0941]. CD-ROM

RISSANEN, Timo. TIMO RISSANEN: FASHION CREATION WITHOUT FABRIC WASTE CREATION. Disponível na internet por http em: <http://zerofabricwastefashion.blogspot.com>. Acesso em 14 nov 2011.

RÜTHSCHILLING, E. A.; ANICET, Evelise. Contextura: processos produtivos sob abordagem Zero Waste. Modapalavra E-periódico UDESC-CEART, Florianópolis, Santa Catarina, 30 jun 2013. Disponível na internet por http em: <http://www.ceart.udesc.br/modapalavra/edicao12/Dossie/contextura_anne_anicet_ e_evelise_ruthschilling.pdf>. Acesso em 20 abr 2014.

SOARES, Vera Lúcia Lins. Evolução da modelagem no design do vestuário: do simples "ritual ancestral" às técnicas. actas de diseño №7 [ISSN: 1850-2032]. IV Encuentro Latinoamericano de Diseño "Diseño en Palermo" Comunicaciones Acadêmicas Buenos Aires, Argentina, 2009. Disponível em Disponível na internet por http em: <http://fido.palermo.edu/servicios_dyc/publicacionesdc/archivos/16_libro.pdf>.

Acesso em 15 abr 2014.

THE DOWSE ART MUSEUM: Yield: Making Fashion Without Making Waste. Disponível na internet por http em: <http://www.dowse.org.nz/News/Latest-News/Yield-MakingFashion-Without-Making-Waste/>. Accesso em 26 jan 2012.

THE PERFECT NOSE: Book Review: Cut My Cote by Dorothy K. Burnham. Disponível na internet por http em: <http://theperfectnose.wordpress.com/2013/01/10/bookreview-cut-my-cote-by-dorothy-k-burnham/>. Acesso em 27 nov 2011.

YIELD. Disponível na internet por http em: <http://yieldexhibition.com/index.html>. Acesso em 22 nov 2011. 